\title{
Prevalence of Amenorrhea Among Undergraduate Females at BUITEMS: A Cross-Sectional Study
}

\section{Nida Tabassum Khan*, Alashba Naudhani}

Department of Biotechnology, Faculty of Life Sciences and Informatics, Balochistan University of Information Technology Engineering and Management Sciences, (BUITEMS), Quetta, Pakistan.

\section{ABSTRACT}

An amenorrhoeic female is characterized when she has missed her menses for two or more months consecutively in a row. Such menstrual-related issue is prevalent in young females that are reproductively active and requires medical attention otherwise complications like infertility, psychosocial developmental delays, and osteoporosis, fractures, etc might result in such adolescent females at a very early age. Therefore it is crucial to diagnose and identify amenorrhea and its contributing factors in young females'. The obtained results of our study suggested that amenorrhea is prevalent among adolescent females that suffer from a high level of stress due to academic burden, hormonal imbalance, dietary deficiency, and premenstrual symptoms.

Key Words: Amenorrhea; Osteoporosis; Infertility; Premenstrual symptoms; Menstrual pattern.

\section{Correspondence Author}

Dr. Nida Tabassum Khan

E-mail: nidatabassumkhan@yahoo.com

Crossref Doi: https://doi.org/10.36437/irmhs.2019.2.6.B

\section{Introduction}

The absence of menstruation in females during the reproductive ages of approximately 12-49 years is called Amenorrhea. [1] In general, if a female does not have menses for two months or more, she has amenorrhea. [2] Studies have shown that a large proportion of the female population of reproductive age suffers from menstruation-related amenorrhea. [3] Menstrual problems not only carry an economic burden but are also one of the most common causes of absenteeism and poor academic performance among young females $[4,5]$. The majority of young females who happen to be undergraduate students reported that they have skipped their periods due to continuous and chronic academic stress related to their studies and exams. [6] Nutritional deficiency is another factor causing amenorrhea because of long term shortage of essential nutrients required by the reproductively active adolescent females [7] On the other hand high prevalence of amenorrhoea was observed in those young females that were involved in athletics due to prolonged decreases in their hormone levels. [8] Menses irregularity is a usual occurrence during teenage however it's not a normal situation and is responsible for causing significant medical illness. [9] Menses patterns can be an indicator of overall health status and self-perception of well-being. [10] Therefore it is essential to understand the various causes of amenorrhea otherwise complications like infertility, psychosocial developmental delays, and osteoporosis, fractures, etc might result in the adolescent females at a very early age. $[11,12]$ 
Therefore this research study aimed to determine the prevalence of amenorrhea among undergraduate females studying at BUITEMS and also to identify those factors that contribute towards such a mensuration problem.

\begin{tabular}{|c|l|c|}
\hline \multirow{2}{*}{ S. No } & Menstrual pattern & $\begin{array}{c}\text { No of students (\%) } \\
(\mathbf{n = 1 0 0})\end{array}$ \\
\hline \multirow{2}{*}{$\mathbf{1}$} & Number of cycle missed & 63 \\
\cline { 2 - 3 } & $\bullet \quad$ None missed & 16 \\
\hline \multirow{2}{*}{$\mathbf{2}$} & $\bullet \quad 1$ months & 21 \\
\hline & -2 or more months (Sign of amenorrhea) & 58 \\
\cline { 2 - 3 } & $\bullet \quad$ Regular & 42 \\
\cline { 2 - 3 } & $\bullet \quad$ Irregular & \\
\hline
\end{tabular}

Table 1: Menstrual pattern of the undergraduate female students

\section{Materials and methods}

This study was a cross-sectional study, conducted among the female undergraduate students studying in different departments at BUITEMS, Quetta, Pakistan. The students were selected at random studying in different departments. Informed consent was obtained from these students keeping the sample size 100.

Inclusion criteria: Adolescent undergraduate female students (aged between 18 and 25 years), who were willing to participate in the study.

Exclusion criteria: Those adolescent undergraduate females that were married was excluded from this study.
The study was conducted with the help of a selfdeveloped amenorrhea identification questionnaire designed to find the prevalence of amenorrhea and its associated contributing factors among undergraduates' females. The questionnaire included items relating to the participants' menstrual pattern (cycle interval in days, menstrual regularity), premenstrual symptoms, eating patterns and stress. Statistical analysis of the data was done by means of Microsoft Excel in 2013. Results

\section{Results}

Table 1 and Graph 1 depicts the menstrual pattern of the adolescent undergraduate females including number of cycle missed and menstrual regularity. 


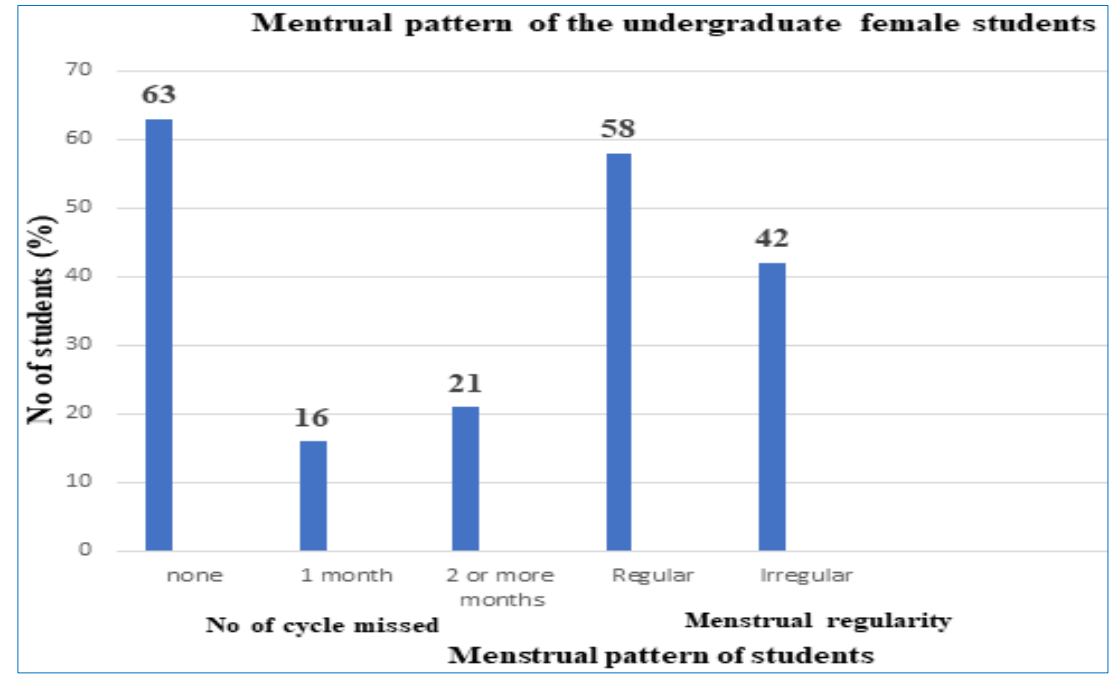

Graph 1: Menstrual pattern of the undergraduate female students

Table 2 and Graph 2 depicts the different Amenorrhea associated premenstrual symptoms suffered by the undergraduate female students.

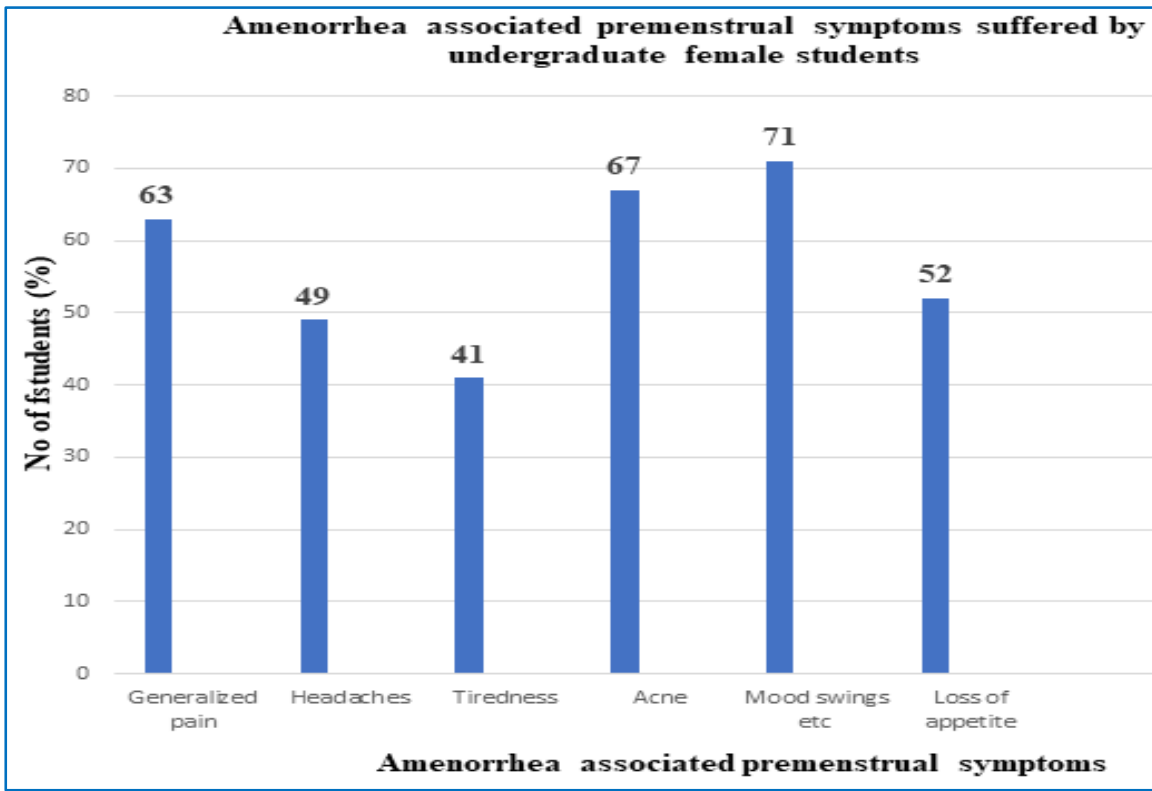

Graph 2: Amenorrhea associated premenstrual symptoms suffered by the undergraduate female students.

Eating patterns of the 100 adolescent undergraduate female students were given in Table 3 and Graph 3. 


\begin{tabular}{|c|c|c|}
\hline S. No & Eating pattern & $\begin{array}{c}\text { No of students } \\
(\%) \\
(n=100)\end{array}$ \\
\hline \multirow[t]{3}{*}{1} & Health condition & \\
\hline & - $\quad$ Balanced & 37 \\
\hline & - $\quad$ Malnourished & 63 \\
\hline \multirow[t]{3}{*}{2} & Exercise & \\
\hline & - $\quad$ Regular & 0 \\
\hline & - Irregular/none & 100 \\
\hline \multirow[t]{3}{*}{3} & Meal times & \\
\hline & - $\quad$ Regular three times a day & 31 \\
\hline & - $\quad$ Irregular i.e. skipping meals & 69 \\
\hline
\end{tabular}

Table 2: Eating patterns of the undergraduate females

\begin{tabular}{|c|l|c|}
\hline S. No & \multicolumn{1}{|c|}{$\begin{array}{c}\text { Amenorrhea associated } \\
\text { premenstrual symptoms }\end{array}$} & $\begin{array}{c}\text { No of students } \mathbf{\%}) \\
(\mathbf{n = 1 0 0 )}\end{array}$ \\
\hline $\mathbf{1}$ & Generalized pains & 63 \\
\hline $\mathbf{2}$ & Headaches & 41 \\
\hline $\mathbf{3}$ & Tiredness & 67 \\
\hline $\mathbf{4}$ & Acne & 71 \\
\hline $\mathbf{5}$ & Mood swings, anger, irritability & 52 \\
\hline $\mathbf{6}$ & Loss of appetite & \\
\hline
\end{tabular}

Table 3: Different Amenorrhea associated premenstrual symptoms 


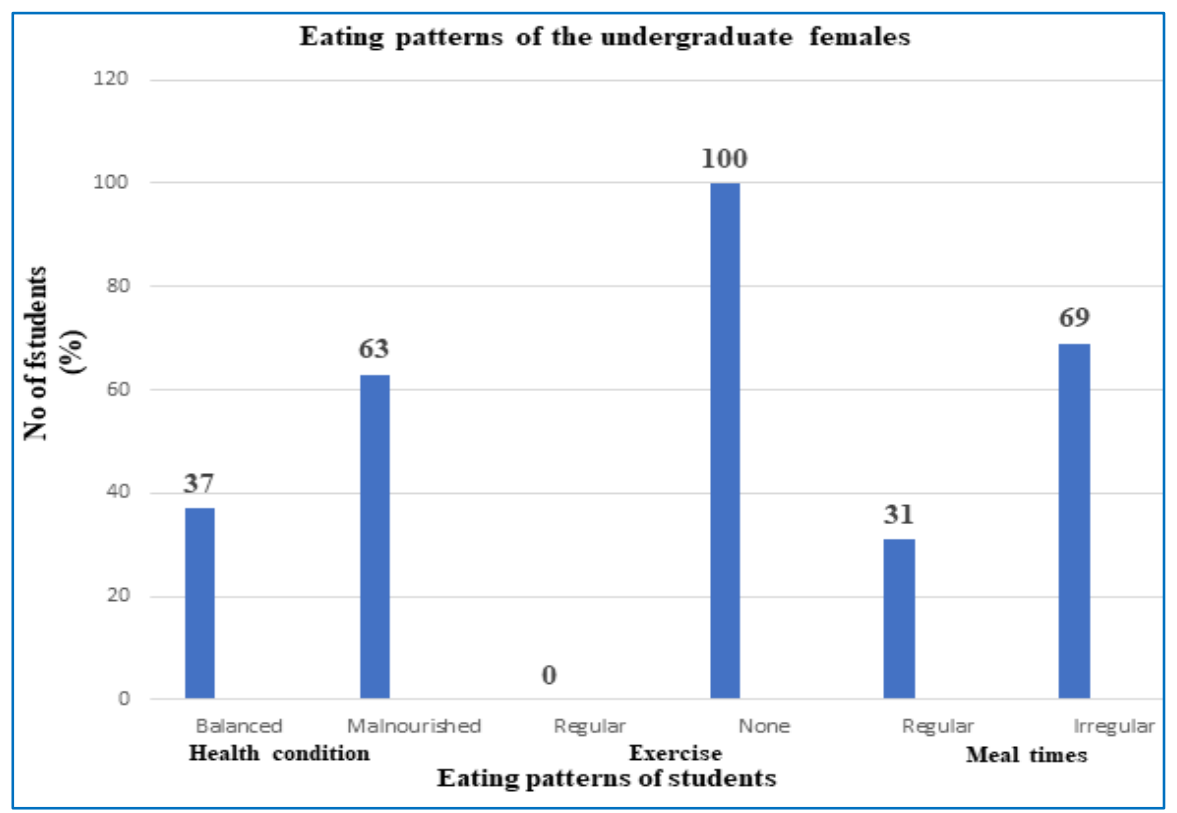

Graph 3: Eating patterns of the undergraduate females

Prevalence of stress among 100 adolescent undergraduate female students were given in Table 4 and Graph 4 .

\begin{tabular}{|c|c|c|}
\hline S. No & Incidence of stress & $\begin{array}{c}\text { No of students (\%) } \\
(\mathbf{n = 1 0 0 )}\end{array}$ \\
\hline $\mathbf{1}$ & $\bullet \quad$ Stressed & 34 \\
\hline $\mathbf{2}$ & $\bullet \quad$ Non-stressed & 66 \\
\hline
\end{tabular}

Table 4: Incidence of stress among undergraduate females

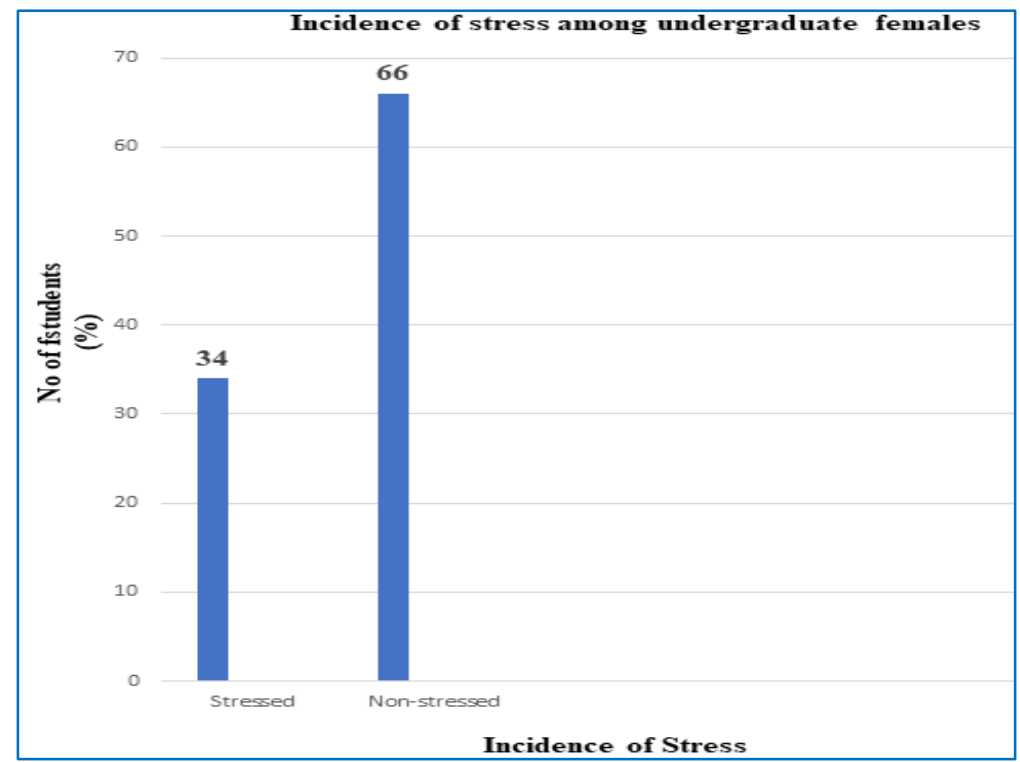

Graph 4: Incidence of stress among undergraduate females 
Prevalence of Amenorrhea among 100 adolescent undergraduate female students were given in Table 5 and Graph 5.

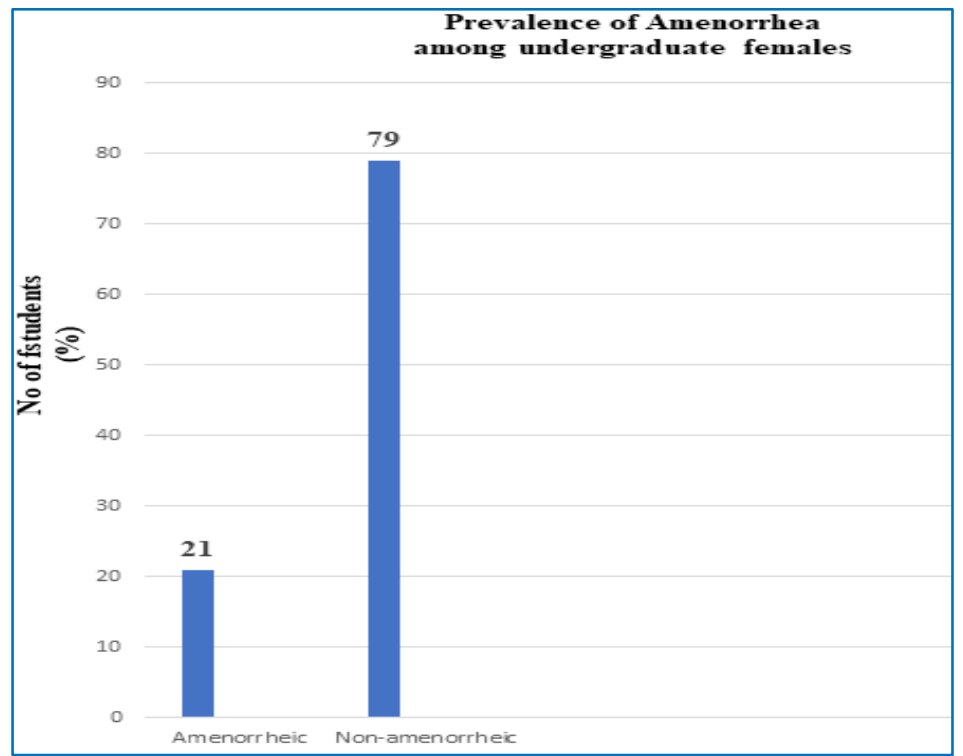

\section{Graph 5: Prevalence of Amenorrhea among undergraduate females}

\section{Discussion}

Our study revealed that the overall prevalence of Amenorrhea is low among the studied female undergraduates as depicted in graph 5 . The result suggested that out of 100 undergraduate females only $21 \%$ were amenorrheic while $79 \%$ were non-amenorrheic. However, a total of $42 \%$ of undergraduate females out of 100 were having irregular menstrual patterns as shown in graph 1 accompanied with apparent premenstrual symptoms (Graph 2). The prime contributing factor responsible for causing amenorrhea in undergraduate females were reported to be stress [13] as 34\% of these undergraduate females were under a high level of stress due to academic burden (Graph 4) as amenorrhea and stress are among the most common health problems in young females $[14,15]$. This study also depicted that females with amenorrhea also suffers from premenstrual symptoms such as $49 \%$ suffered headache,63\% generalized pain, $67 \%$ acne and a large proportion of females were troubled by mood swings 71\% (Graph 2) which makes it difficult for these females to cope up with their daily routine causing discomfort and distress $[16,17]$. Varying prevalence of premenstrual symptoms can be caused by abnormal functioning of the hypothalamic-pituitary-adrenal axis (HPA), hormonal imbalance, nutritional defects, and environmental factors [18]. A possible physiological mechanism responsible for irregular menstruation and amenorrhea in these young females with associated pre-menstruation symptoms can be prolonged activation of the hypothalamic-pituitary-adrenal axis by stress, which may alter hormonal profiles, resulting in the disruption of normal ovulation and menstrual cycles $[19,20]$. However, there were certain limitations in this study such as factors like body mass index, lack of sleep, socioeconomic status of the studied females were not considered and moreover, this studied was based on data obtained through the questionnaire only and no medical examination was performed.

\section{Conclusion}

This research study concluded that amenorrhea is a menstrual related health issue that is triggered by high stress among undergraduate females 
studying at BUITEMS. In addition to stress factors like eating patterns, premenstrual symptoms, etc were also characterized in amenorrheic females. Therefore it is important that young females should be provided with therapeutic counseling on stress management and menstrual issues at their respective institutions to help them deal with such distress.

\section{References}

1. Nawaz, G., \& Rogol, A. D. (2018). Amenorrhea. In StatPearls [Internet]. StatPearls Publishing.

2. Macut, D., Milutinović, D. V., Rašić-Marković, A., Nestorov, J., Bjekić-Macut, J., \& Stanojlović, 0. (2018). A decade in female reproduction: an endocrine view of the past and into the future. Hormones, 17(4), 497505.

3. Deliwala, K. J., Shah, H. H., Shah, B. S., Goswami, H. M., Shah, P. K., \& Patil, S. (2013). Evaluation of menstrual problems among urban females of Ahmedabad. Journal of Clinical Research Letters, 4(1), 49.

4. Bitzer, J., Tschudin, S., \& Stadlmayr, W. (2005). Menstruation and its impact on women's health. Zentralblatt fur Gynakologie, 127(5), 282-287.

5. Houston, A. M., Abraham, A., Huang, Z., \& D'Angelo, L. J. (2006). Knowledge, attitudes, and consequences of menstrual health in urban adolescent females. Journal of Pediatric and Adolescent Gynecology, 19(4), 271-275.

6. Issa, B. A., Yussuf, A. D., Olatinwo, A. W. O., \& Ighodalo, M. (2010). Premenstrual dysphoric disorder among medical students of a Nigerian university. Annals of African medicine, $9(3)$.

7. Garfinkel, P. E., Lin, E., Goering, P., Spegg, C., Goldbloom, D., Kennedy, S., ... \& Woodside, D. B. (1996). Should amenorrhoea be necessary for the diagnosis of anorexia nervosa? Evidence from a Canadian community sample. The British Journal of Psychiatry, 168(4), 500-506.

8. Helen de Pinho. (1993). Agenda: Empowering Women for Gender Equity., Recreation and Leisure,No. 17 , pp. 51-54.

9. Golden, N. H., \& Carlson, J. L. (2008). The pathophysiology of amenorrhea in the adolescent. Annals of the New York Academy of Sciences, 1135(1), 163-178.

10. WIKSTEN-ALMSTRÖMER, M. A. R. I. A. N. N. E., Linden Hirschberg, A., \& Hagenfeldt, K. (2007). Menstrual disorders and associated factors among adolescent girls visiting a youth clinic. Acta obstetricia et gynecologica Scandinavica, 86(1), 65-72.

11. Reindollar, R. H., Novak, M., Tho, S. P., \& McDonough, P. G. (1986). Adult-onset amenorrhea: a study of 262 patients. American journal of obstetrics and gynecology, 155(3), 531-541.

12. Nagel, G., Altenburg, H. P., Nieters, A., Boffetta, P., \& Linseisen, J. (2005). Reproductive and dietary determinants of the age at menopause in EPIC-Heidelberg. Maturitas, 52(3-4), 337-347.

13. Nisar, N., Zehra, N., Haider, G., Munir, A. A., \& Sohoo, N. A. (2008). Frequency, intensity and impact of premenstrual syndrome in medical students. J Coll Physicians Surg Pak, 18(8), 481-4.

14. Cohen, S., Kamarck, T., \& Mermelstein, R. (1983). A global measure of perceived stress. Journal of health and social behavior, 385-396.

15. Allsworth, J. E., Clarke, J., Peipert, J. F., Hebert, M. R., Cooper, A., \& Boardman, L. A. (2007). The influence of stress on the menstrual cycle among newly incarcerated women. Women's Health Issues, 17(4), 202209.

16. Direkvand-Moghadam, A., Sayehmiri, K., Delpisheh, A., \& Kaikhavandi, S. (2015). (PMS)-A Systematic Review and MetaAnalysis Study.(Published in Journal of 
Clinical and Diagnostic Research. 2014 Feb: 8 (2):). 106-109. JCDR, 8024-6295.

17. Raval, C. M., Panchal, B. N., Tiwari, D. S., Vala, A. U., \& Bhatt, R. B. (2016). Prevalence of premenstrual syndrome and premenstrual dysphoric disorder among college students of Bhavnagar, Gujarat. Indian Journal of psychiatry, 58(2), 164.

18. Eriksson, O., Wall, A., Marteinsdottir, I., Ågren, H., Hartvig, P., Blomqvist, G., ... \& Naessén, T. (2006). Mood changes correlate to changes in brain serotonin precursor trapping in women with premenstrual dysphoria. Psychiatry Research: Neuroimaging, 146(2), 107-116.

19. Zhou, M., Wege, N., Gu, H., Shang, L., Li, J., \& Siegrist, J. (2010). Work and family stress is associated with menstrual disorders but not with fibrocystic changes: Cross-sectional findings in Chinese working women. Journal of occupational health, 52(6), 361-366.

20. Tsigos, C., \& Chrousos, G. P. (2002). Hypothalamic-pituitary-adrenal axis, neuroendocrine factors and stress. Journal of psychosomatic research, 53(4), 865-871.

How to cite this Article: * Nida Tabassum Khan; Prevalence of Amenorrhea Among Undergraduate Females at Buitems: A Cross-Sectional Study

Int. Res. Med. Health Sci., 2019; (2-6): 74-81

Source of Support: Nil, Conflict of Interest: None declared.

Received: 08-12-2019; Revision: 26-12-2019; Accepted: 28-12-2019 